\title{
Priming the Governance System for Climate Change Adaptation: The Application of a Social-Ecological Inventory to Engage Actors in Niagara, Canada
}

\author{
Julia Baird $^{1}$, Ryan Plummer ${ }^{1,2}$ and Kerrie Pickering ${ }^{1}$
}

\begin{abstract}
Climate change adaptation presents a challenge to current top-down governance structures, including the tension between provision of public goods and actions required by diverse stakeholders, including private actors. Alternative governance approaches that facilitate participation and learning across scales are gaining attention for their ability to bring together diverse actors across sectors and to foster adaptive capacity and resilience. We have described the method and outcomes from the application of a social-ecological inventory to "prime," i.e., hasten the development of, a regional climate change adaptation network. The social-ecological inventory tool draws on the social-ecological systems approach in which social and ecological systems are considered linked. The tool bridges the gap between conventional stakeholder analysis and biological inventories, drawing on a social-ecological systems approach, and incorporates local knowledge as an explicit component. The process, which is dynamic and iterative, includes six phases: preparations, preliminary identification, identification of key individuals, interviewing, reviewing and enriching the inventory, and engagement. By considering the social and ecological aspects of a system, a more comprehensive inventory is achieved that provides a foundational platform to facilitate or support climate change adaptation processes that are participatory and learning oriented. Although socialecological inventories have been used for ecosystem management, the intent of this research was to understand the potential of the tool for climate change adaptation. A social-ecological inventory was undertaken in the Niagara Region of Canada to assemble and facilitate a regional governance group to champion climate change adaptation. Moreover, the social-ecological inventory was purposefully undertaken as the initial step in priming the governance system and led into an adaptive comanagement process for climate change adaptation. Early indicators suggest that the social-ecological inventory has been instrumental in facilitating a multisectoral adaptive comanagement governance approach to climate change in the Niagara Region.
\end{abstract}

Key Words: adaptive comanagement; climate change adaptation; local knowledge; social-ecological system

\section{INTRODUCTION}

Engendering effective and efficient responses to climate change is a considerable challenge. The window for responding, including by mitigation and adaptation efforts, to climate change is thus closing quickly, and the emphasis on adaptation is crucial (Parry et al. 2009). Thus, the imperative nature of this challenge is being brought sharply into focus. Past emissions combined with present global emissions are cause to reconsider initial predictions of temperature increases, and the probability of a $4^{\circ} \mathrm{C}$ rise from preindustrialization is gaining acceptance (Parry et al. 2009, Smith et al. 2009). Extreme weather and climate events will accordingly be altered in terms of intensity, frequency, duration, and timing (Parry et al. 2009, IPCC 2012). Although anticipating the precise impacts from such temperature increases becomes very difficult because of the interconnectedness of systems and uncertainties of feedback loops (Adger and Barnett 2009), the impacts of extreme events often push communities beyond their coping abilities (Smit and Wandel 2006). Not only are the impacts of climate change unavoidable by the most stringent mitigation efforts (Klein et al. 2007), but questions are being raised about the prospects for adaptation under these new projections (Adger and Barnett 2009).

Adaptation research has evolved considerably from being a handmaiden to impacts research on mitigation to a burgeoning area of research and policy (see Burton et al. 2002 for a summary). The International Panel on Climate Change (IPCC) understands adaptation to involve "adjustment in natural or human systems in response to actual or expected climatic stimuli or their effects, which moderates harm or exploits beneficial opportunities"
(2001:982). Adger et al. (2007) assess adaptation practices, options, constraints, and capacity in the contributions of Working Group II to the Fourth Assessment Report of the IPCC. The breadth of possible adjustments in different systems is vast, multifaceted, and often taking place for reasons beyond just climate change. The breadth and nature of these adjustments leads van Nieuwaal et al. (2009:8) to conclude that:
... adaptation is not only, or particularly, a technical issue, but that it can be characterised as a complex social interaction process and that it should be studied as such. Only then can adaptation to climate change also be regarded as a window of opportunities. Dealing with climate adaptation not only demands a rethink of how we arrange our social-ecological or socio-technical systems but also how we govern them.

In establishing that adaptation is a matter of governance, van Nieuwaal et al. (2009) draw on the popular narrative of shifting from "government to governance" to convey the decade-long trend away from top-down government to less formalized forms of governance. Several types or models of governance exist, e.g., state, market, and community, which often come together or hybridize in practice (Glasbergen 1998, Lemos and Agrawal 2006). We are specifically concerned with adaptive systems of governance. Adaptive systems of governance coincide with Lee's (2003) conceptualization of "the new governance" and are defined as "... a polycentric form of social coordination in which actions are coordinated voluntarily by individuals and organizations with self-organizing and self-enforcing capabilities" (Folke et al. 
2005:449). Adaptive governance recognizes that systems are inherently dynamic and unpredictable (Gunderson and Light 2006). Institutional arrangements that assume and manage for change as well as being integrative in orientation are thus emphasized (Gunderson and Light 2006). Adaptive governance draws attention to the establishment of networks that connect actors at multiple scales and that enable collaboration, learning, experimentation, knowledge exchange, and decision making (Folke et al. 2005, Olsson et al. 2006).

In their review of adaptive governance of social-ecological systems, Folke et al. (2005:444) argue that "... adaptive governance is operationalized through adaptive co-management systems." Adaptive comanagement (ACM) is frequently cited as an example of adaptive governance in practice (e.g., Nelson et al. 2007, Armitage et al.2009), and its potential applicability to community climate change adaptation is starting to be recognized (e.g., Locatelli et al. 2008, May and Plummer 2011). May and Plummer (2011), for example, argue that the transition of conventional risk management standards in the direction of participation, learning, and governance for climate change adaptation can be accelerated by infusing the collaborative and adaptive spirit of ACM. ACM, however, is recognized as a process that may require considerable time to mature and develop (Armitage et al. 2009, Berkes 2009a).

The need for innovative tools for stakeholder involvement and specific institutional mechanisms to support adaptation outcomes (Tompkins and Eakin 2012) cannot be underestimated. Collaborative governance approaches bring together diverse actors at various scales including those from "civil society," or the private domain, who were previously not involved (Kooiman 2003), creating an appropriate dynamic for ACM (Folke et al. 2005, Berkes 2009a). Effectiveness, efficiency, and legitimacy are cited as important characteristics of collaborative governance involving diverse actors (Witte et al. 2003). However, in the context of climate change adaptation, the "goods" provided as a result of adaptation efforts are largely public in nature, and the tension between private interests and action and the provision of public goods may threaten to derail ACM processes (Tompkins and Eakin 2012). Despite this tension, climate change adaptation "will require the concerted efforts of decision makers in diverse institutions across multiple scales" (Agrawal 2010:179) because the effects of climate change are caused by public and private actors, and costs are socialized at a global scale and experienced at a local scale (Lemos and Agrawal 2006).

Tools that can facilitate synergies between the public and private domains, and accelerate the initiation and evolution of adaptive governance for climate change adaptation, are thus of growing importance. We contribute to the "modes of governance and available instruments" theme of the Special Feature on the Governance of Adaptation by considering the social-ecological inventory as a tool for priming the governance system for climate change adaptation, specifically to bring about ACM in socialecological systems. That is, we focus on the social-ecological inventory as a tool to prepare the system and accelerate the development of an ACM process, given the following: (1) ACM is potentially an important governance practice for climate change adaptation; and (2) it requires considerable time to mature, whereas the window of opportunity for engaging in climate change adaptation is narrow. The exploration is structured into four parts: the conceptual rationale for the social-ecological inventory and the procedural steps that comprise the tool, a case study of the Niagara Region of Canada in which an socialecological inventory was undertaken as a precursor to an ACM process for climate change adaptation, the lessons learned from applying the social-ecological inventory in the Niagara Region, and conclusions that identify future avenues for research concerning social-ecological inventories and adaptive governance for climate change adaptation.

\section{THE SOCIAL-ECOLOGICAL INVENTORY TOOL}

A suite of processes and tools to include a range of actors in governance approaches exists and has been described in the literature. For example, a model of interactive policy making introduced by Driessen et al. (2001) focuses on the task-based selection of actors to engage and the negotiation of diverse perspectives of those involved in the process. Driessen et al. (2001) highlighted the importance of a cyclical and iterative approach to governance. Another tool, scenario-based stakeholder engagement, was developed by Tompkins et al. (2008) as a means of identifying individuals and groups with a direct stake in, or a role in governance of, specific resources. Following identification and selection of stakeholders, the approach is used to uncover the preferences, views, and opinions of the stakeholders regarding the resources in question and subsequently incorporate this information in decision-making processes (Tompkins et al. 2008). Multicriteria analysis, a well-recognized approach used for weighing impacts of different natural resource management policy options, has also been used in stakeholder inventory and analysis (Qureshi et al. 1999). Similar to scenario-based stakeholder engagement, this approach enables researchers to obtain important information on stakeholder values, views, and preferences concerning complex environmental decisions (Qureshi et al. 1999, Kiker et al. 2005). These approaches and others, including stakeholder analysis (e.g., Mushove and Vogel 2005, Prell et al. 2009), focus on the interests, attributes, and relationships of and among potential participants in governance (Mushove and Vogel 2005). These tools do not include explicit consideration of the contributions of diverse knowledge to the governance process.

Conventional tools to conduct inventories have concentrated on either natural systems or social systems. Bridging conventional ecological inventories and stakeholder analysis for initiating a participatory process to enhance resource management, with an explicit consideration of local knowledge, is the raison d'être for the social-ecological inventory (Schultz et al. 2007:141):
We designed a method, a social-ecological inventory, to identify these local steward groups and their activities, with the ultimate aim of drawing on their experience to enhance ecosystem management at the landscape level. Such an inventory complements stakeholder analyses and biological and ecological inventories, and assesses existing management systems behind the generation of ecosystem services, thus providing a starting point for participation.

Ecological inventories aim to document the biophysical landscapes and generally omit the social processes influencing the natural system. Stakeholder inventories and analysis conversely focus on gathering information from all stakeholders that affect 
the decision-making process but tend not to account for biophysical components. Conceptual touchstones for the socialecological inventory come from the social-ecological systems approach and the benefits from incorporating local knowledge into conservation efforts. The social-ecological systems approach primarily extends from ecology and complexity theory (Cummings 2011). This integrative view stresses the linked nature of social and ecological systems, i.e., a social-ecological inventory, and argues that their delineation is artificial and arbitrary (see Berkes and Folke 1998, Berkes et al. 2003). Both social and ecological components of a system must be simultaneously taken into account to understand a system (Berkes et al. 2003, Folke et al. 2005, Gallopín 2006). Although specific components are singled out for greater understanding, such as through ecological inventories and stakeholder analyses, it is through the integration of both systems that the complex relationship between components becomes apparent (Gallopín 2006).

Combining different types of knowledge is a critical factor required for social-ecological systems during periods of rapid change (Olsson et al. 2007). Understanding and navigating the complexities and dynamics of social-ecological systems is information intensive, and the knowledge required for management is held among a diverse array of individuals and organizations (Olsson et al. 2007). Although local knowledge was considered less reliable than scientific knowledge because it blends knowledge and beliefs, and is embedded with cultural and social norms (Gadgil et al. 2003), its potential to enhance conservation efforts is now being advanced (Gadgil et al. 1993, Folke et al. 2005, Berkes 2009b). Local actors, as a result of their close connection with the social-ecological system, can identify linkages among changes in the system that other actors may not (see, e.g., Olsson et al. 2007) and can provide local expertise and historical/baseline information not available elsewhere (Folke et al. 2003). In practice, the line between local/traditional knowledge and scientific knowledge can be blurry and difficult to separate (Folke et al. 2003).

The importance of complementing and combining scientific knowledge with local knowledge about ecosystem dynamics and social dynamics is increasingly being recognized in environmental management (Gadgil et al. 2003, Schultz et al. 2007). Recognizing the potential gains from incorporating local knowledge, and the shortcomings of conventional inventories, Schultz et al. (2007) pioneered the development of the social-ecological inventory tool in Kristianstads Vattenrike in Sweden. The intent was to identify local steward groups acting outside official management plans and to utilize their collective knowledge and activities in enhancing ecosystem management (Schultz et al. 2007). Local stewards were identified, insights about the social-ecological landscape were gained, and an ACM process emerged. Although the purpose of the social-ecological inventory tool was not explicitly to create the conditions for, or to catalyze, an ACM process specifically, the tool was created to provide "a starting point for participation" (Schultz et al. 2007:141), and in the case of Kristianstads Vattenrike, an ACM process did result. Inspired by the initial experiences with the social-ecological inventory in Kristianstads Vattenrike, an intensive workshop was undertaken by a consortium of researchers to more fully develop the tool. The outcome of the workshop was the creation of a socialecological inventory workbook (Schultz et al. 2011), which offers a guide to researchers and practitioners.
Although separated into six phases for the purpose of describing the process, the social-ecological inventory phases occur concurrently and continuously incorporate feedback, and the process is dynamic and iterative. Figure 1 illustrates the six phases of the social-ecological inventory process. In the initial preparatory phase, the goals are defined, ground rules for researchers are set, and relevant ethics protocols are completed. In the second phase of preliminary identification, various sources of information, e.g., the Internet, local organizations, land-use maps, local telephone books, and so forth, are used to generate a list of potentially important actors. The third phase identifies key informants: individuals involved in activities related to climate change and, when linked to an organization, knowledgeable about their organization's activities. Stakeholders on the preliminary list are contacted, and inquiries are made regarding their networks, interests, knowledge, and activities. Key informants often suggest other individuals and organizations to contact. The frequency with which actors are identified is important because those cited most frequently are potentially critical stakeholders in the area. The fourth phase involves conducting interviews with key informants. The interviewing process creates an opportunity to gain in-depth insights about the values and motives of the interviewees, understand their knowledge, develop a historical perspective on activities in which the interviewees are engaged, and discover networks germane to the issues. During this phase, actor interest in the aims and engagement part of the research can be created. Phase five, enriching the picture, is a time to pause and reflect on the information gathered to reveal emerging trends, insights, issues, and gaps in knowledge. In the final phase of engagement, a platform for dialogue is provided for the actors to interact and address common concerns. Engagement may take many forms, such as a workshop, seminar, or ACM process.

\section{PRIMING THE GOVERNANCE SYSTEM FOR CLIMATE CHANGE ADAPTATION: A CASE STUDY OF THE NIAGARA REGION, CANADA}

ACM has been applied in several resource and environmental management contexts (e.g., Plummer 2006, Olsson et al. 2007, Cundill and Fabricius 2009, Kallis et al. 2009). The prospects of ACM as a process for climate change adaptation are being considered (Locatelli et al. 2008, May and Plummer 2011) as a way to operationalize adaptive governance and address the complexities and uncertainties associated with social-ecological systems. The substantial amount of time required for ACM to mature and develop (Armitage et al. 2009, Berkes 2009a) poses a particular challenge because the time frame for initiating planned climate change adaptation is closing quickly.

A case study was thus undertaken to investigate if the governance system for climate change adaptation could be primed by undertaking a social-ecological inventory. The tool was specifically applied in the Niagara Region to include local knowledge as a key factor in understanding the social-ecological landscape and as a tool to catalyze the initiation of an ACM process for climate change adaptation. The six phases of the social-ecological inventory process (Fig. 1) were followed. Interviews were conducted with key informants and focused on three areas of investigation: (1) perceptions of climate change impacts in Niagara, organizational capacity for adaptation, and adaptation leadership; (2) specific activities related to climate change and the rationale for these efforts; and (3) networks and relationships with other actors in Niagara related to climate 
Fig. 1. Phases of the social-ecological inventory.

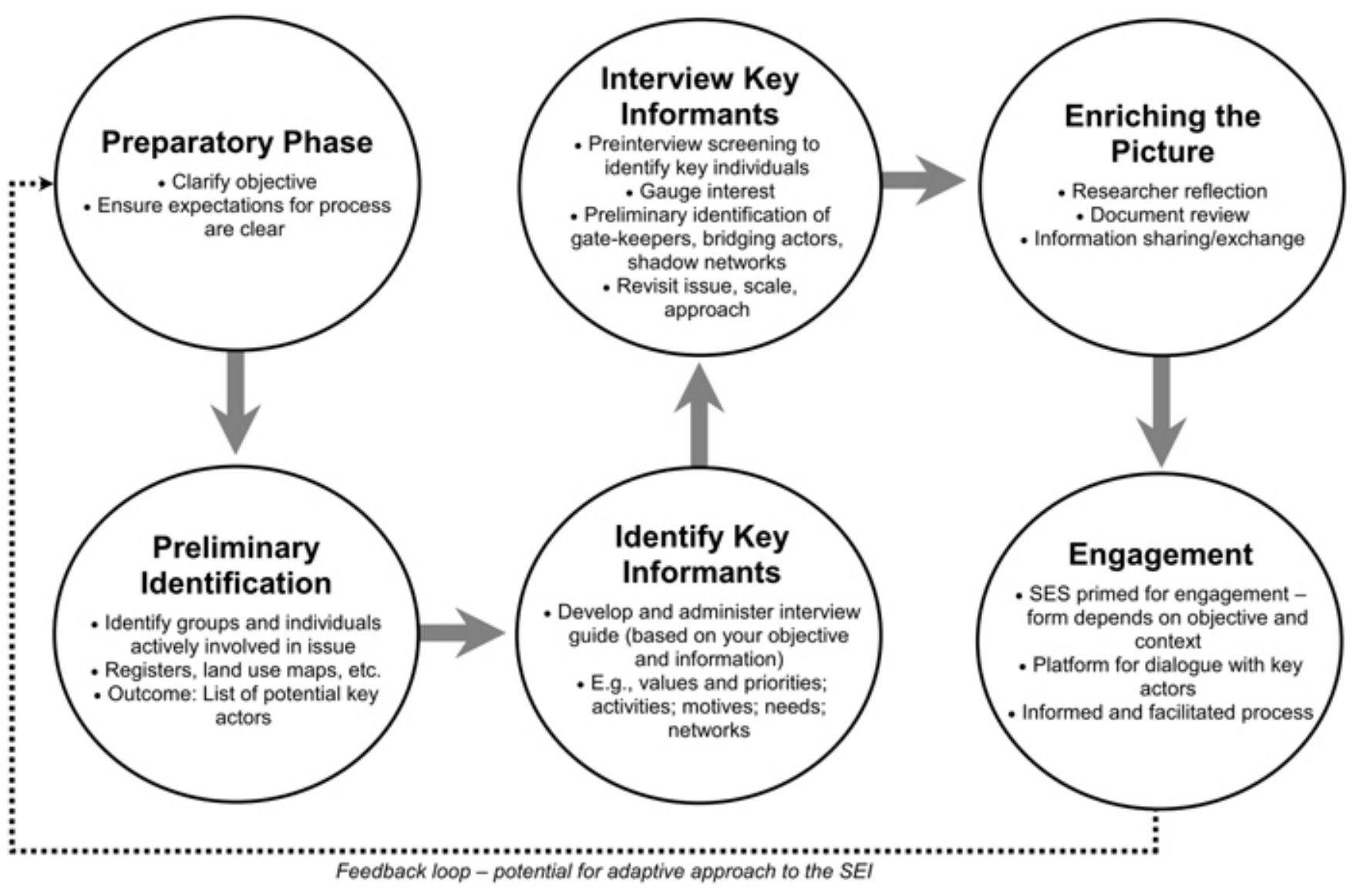

change. Using a snowballing technique to continuously identify key informants, a total of 38 actors were interviewed from 33 organizations in the Niagara Region over a 6-month period. The key informants identified and interviewed using the socialecological inventory comprised 6 general affiliation categories: municipal $(29 \%)$, education and media $(18 \%)$, environmental management $(16 \%)$, nongovernmental organizations $(16 \%)$, business and agriculture (11\%), and emergency management $(10 \%)$. Interviews were carried out in person or over the phone, and each took between 30 and 45 minutes. The qualitative data from the open-ended interviews were then coded, grouping similar information into categories with shared characteristics (Saldaña 2009).

Niagara was selected for the case study because Environment Canada investigated the effects of climate variability on the region in 1998 and an existing entity focused on climate change adaptation was not evident. The Niagara Region covers $1852 \mathrm{~km}^{2}$ and is located in southern Ontario between Lake Ontario and Lake Erie. Approximately 431,346 people live in Niagara (Statistics Canada 2012). The Niagara Region encompasses a portion of the Niagara escarpment, which is a UNESCO Biosphere Reserve. The two Great Lakes have a moderating effect on the climate, which makes the area an ideal location for agricultural production, including tender fruit and Ontario's largest wine-growing area. Niagara Falls is the major tourist attraction in the region, attracting more than 30 million visitors who spend an estimated Can\$2.3 billion annually (NEDC 2010). The region has a strong transportation sector with the Welland Canal system running across it to permit the movement of vessels between the Great Lakes. Historically, Niagara also had a strong automotive and manufacturing industry. However, this industry is in decline, and Niagara is repositioning itself with a focus on alternative energy, interactive media, and bioproducts (NEDC 2010).

Results from the social-ecological inventory are presented subsequently. The following subheadings correspond to each of the three main areas of investigation. In the first main area, questions were asked to actors regarding their perceptions of climate change adaptation. The underlying intent of this line of questioning was to reveal insights about their knowledge, beliefs, and values regarding climate change adaptation. The second main area sought to identify present activities relating to climate change on the landscape and to understand the rationale of actors for these efforts. The third main area of inquiry investigates existing collaborations and networks. Results are conveyed in terms of major and minor themes arrived at through the coding process. Examples are used throughout the results to convey the richness of the information gained. 


\section{Actors' perceptions about climate change adaptation}

In an effort to gain insights into local knowledge about the impacts of climate change, all interviewees were asked if they had observed any changes in Niagara that could be potentially related to climate change. Observed changes in Niagara that could be related to climate change were reported by most of the interviewees. Ten themes emerged from coding these responses. The most common observation was increase in seasonal temperatures, i.e., warmer winters and hotter summers. Change in insect populations, e.g., ticks and gypsy moths, was the second most common observation. Increases in extreme weather events, e.g., tornado and storm activity and summer heat waves, and reduced water levels in the Great Lakes were also commonly reported.

In an effort to further understand the state of local knowledge about climate change and how impacts may influence the Niagara social-ecological system, interviewees were asked to identify sectors and/or environmental features particularly exposed to climate change. Agriculture was identified by more than half of the interviewees, who also observed that this sector was extremely sensitive to environmental change. The sectors of tourism and public health were identified by almost one-third of interviewees as also being particularly exposed to the impacts of climate change. Specific exposure concerns for the public health sector included heat waves, storms, non-point-source pollution from agricultural runoff associated with flash floods, diminishing water quality and quantity, invasive species, and changing flu seasons. Water resources were an environmental feature perceived to be particularly exposed to the impacts of climate change by approximately one-quarter of all interviewees. This exposure came from changing weather patterns, which impact water quantity, i.e., water recharge, as well as water quality. Some interviewees also perceived Niagara's transportation system and infrastructure to be exposed to impacts of climate change, such as changing freeze-and-thaw cycles and declining lake levels. Recreation was also perceived to be susceptible to exposure because of increased algae growth, diminished water quality, reduced health of fish stocks, and declining lake levels. Onequarter of all those interviewed perceived all aspects of the economy and ecosystems in Niagara to be exposed to climate change impacts.

Interviewees were asked about the relevance of climate change to their professional work. The relevance of the issue was queried to understand how interviewees perceived climate change impacts in relation to their work. Relevance from this perspective also may give an indication of interviewees' values (Sjöberg 2000). Three major themes were identified from the responses. The first, and most common, theme was labeled "directly relevant." It was expressed most strongly by interviewees from environmental nongovernmental organizations, education and media, and business and agriculture. Interviewees with responses fitting into this theme considered climate change impacts to directly affect their work. The second theme, "indirectly relevant," was expressed most strongly by interviewees from municipalities and those associated with emergency management. Within this theme, a range of perceptions were expressed by interviewees who considered climate change an issue that would be directly relevant to their work in the future because of its political importance and emerging impacts, directly relevant to authorities beyond the municipal level, or only occasionally relevant to their daily work.
The remaining responses constituted the third theme of "not relevant"; interviewees did not perceive climate change as an issue with any relevance to their work. Often, interviewees representing the same stakeholder group held differing perceptions of the relevance of climate change to their work.

Responding to climate change requires the capacity for adaptation. In this regard, interviewees were asked if they perceived local institutions and organizations involved in environmental management, protection, or risk management to have the capacity to adapt to climate change. Many interviewees, most representing municipalities, business and agriculture, and education and media, perceived some capacity for the Niagara Region to adapt to climate change. Interviewees often expressed that this capacity was contingent upon certain conditions before it could be realized. Necessary conditions described to achieve the capacity for climate change adaptation included more collaborative approaches to planning, adequate information about potential impacts, a supportive political environment and commitments, and strong leadership. Interviewees representing nongovernmental organizations and emergency management generally perceived little to no capacity for adaptation to climate change in Niagara. Responses by this group identified a lack of specific policy direction provincially and the absence of necessary resources to undertake adaptation planning.

Leadership is an essential component for building the capacity for adaptation, and interviewees were asked if they perceived there to be leadership for adaptation to climate change in Niagara. Coding the responses to this question revealed a disjuncture in perceptions regarding leadership. The Regional Municipality of Niagara was perceived as having demonstrated leadership by its recently initiated efforts on climate change, or else it was perceived as being best positioned to provide leadership because of resource availability. Interviewees from municipalities in particular considered adaptation as a natural fit for the regional government. However, interviewees with municipal affiliations constituted the largest proportion of stakeholders in the social-ecological inventory, and when the responses to this question were reanalyzed without their inclusion, the dominant perception was that no current leadership is present in Niagara regarding climate change adaptation. Reasons given for this absence of leadership included a lack of knowledge to facilitate leadership and an absence of collaborative action in adaptation-related efforts. The Niagara Peninsula Conservation Authority was identified by some interviewees, particularly environmental managers, as an organization with the potential to provide leadership in the future.

\section{Climate change activities and efforts}

A major focus of the social-ecological inventory was to identify current practices through which stakeholders interact with the ecosystem, manage environmental features, and address environmental risks. Consistent with the social-ecological systems perspective, these practices are important mechanisms to connect stakeholders to the landscape and provide a base from which actions to address climate change more specifically can be derived. Interviewees were thus asked to identify key practices within their organization regarding environmental management, protection, and risk management. Key practices identified by interviewees were coded and grouped into similar categories. Table 1 conveys the categories of practices presented in descending order of the 
Table 1. Categories of practice.

\begin{tabular}{|c|c|}
\hline Category of Practice & $\begin{array}{l}\text { Description of Category of Practice } \\
\text { (in order of frequency of reporting by interviewees) }\end{array}$ \\
\hline $\begin{array}{l}\text { Policy development \& sustainability } \\
\text { planning }\end{array}$ & $\begin{array}{l}\text { Policy development based on the general principles of sustainability and environmental best management } \\
\text { practices }\end{array}$ \\
\hline Education & $\begin{array}{l}\text { Education of the public about ecosystem functions, vulnerabilities, weather related risks, and carbon } \\
\text { reduction practices }\end{array}$ \\
\hline Water protection & Protection of surface water and groundwater resources and areas of recharge \\
\hline Carbon management & Efforts to reduce carbon emissions internally and externally \\
\hline Environmental regeneration & $\begin{array}{l}\text { Restoration of land, water quality, wildlife habitat, wetland and forest functions, and other ecosystem } \\
\text { functions }\end{array}$ \\
\hline Resource conservation & Protection and conservation of natural resources, wildlife habitat, and ecosystem functions \\
\hline Emergency response & $\begin{array}{l}\text { Responding to weather related/and environmental emergencies such as heat wave, storm, fire, flood, spill, } \\
\text { and air pollution }\end{array}$ \\
\hline Shoreline protection & Protection of shorelines along lakes and rivers from erosion, bacteria and contamination \\
\hline Oversight and enforcement & Environmental oversight, practices, and guidelines provided by other agencies / organizations \\
\hline Natural systems/corridors planning & Planning to foster and protect natural heritage systems such as wildlife and forest corridors \\
\hline Public health \& weather monitoring & $\begin{array}{l}\text { Monitoring of environmental conditions and responding to environmental threats to public health (i.e. } \\
\text { heat wave alerts) }\end{array}$ \\
\hline Adaptation to environmental change & $\begin{array}{l}\text { Environmental management practices that take into account and anticipate changing environmental and } \\
\text { climatic conditions }\end{array}$ \\
\hline Planning for risk management & $\begin{array}{l}\text { Planning for risks associated with environmental hazards and extreme events (i.e. identifying and analyzing } \\
\text { risks, spill preparedness, evacuation planning, fire prevention) }\end{array}$ \\
\hline Agriculture planning & Predominantly related to irrigation system planning \\
\hline
\end{tabular}

number of interviewees who reported the practice. Sustainability planning and public education emerged as the practice categories reported most often. Sustainability planning was often reported by municipal stakeholders, whereas public education practices were reported by interviewees in emergency management, environmental nongovernmental organizations, and education and media. The categories of adaptation to environmental change and planning for risk management were reported by few interviewees.

In an effort to probe current actions in response to climate change in Niagara, interviewees were asked to share their knowledge of any efforts related to climate change within their organization. The activities revealed by the interviewees were then coded according the intent of their efforts. Four themes emerged from the analysis. The first theme was labeled "adaptation" and encompassed efforts such as planning for extreme weather-related emergencies and changing environmental conditions. Adaptation activities were undertaken to some extent by all stakeholder groups except education and media. The second theme was labeled "mitigation," and most of the activities reported by stakeholder groups fit within this theme. It encompassed efforts to manage or reduce corporate carbon emissions, sequester carbon, and develop/implement "green" energy practices "Research on the impacts of climate change" emerged as a third theme. Municipal stakeholders and environmental managers in particular explained that efforts to research impacts are an important precursor to action. The final theme was labeled "education and consultation with the public." Responses from stakeholders in the education and media sector highlighted the information on mitigation practices that was delivered through their respective organizations.

\section{Actor networks and relationships related to climate change}

Revealing existing collaborative relationships and networks among stakeholders is a key aspect of the social-ecological inventory. Interviewees were asked to identify other organizations with whom they collaborate concerning environmental management, protection, or risk management. Collaboration within each respective sector was most common. Collaboration among sectors varied considerably. The environmental management sector reported the greatest number of collaborations and was connected to each of the other sectors except emergency management. Conversely, the business and agriculture sectors reported the fewest number of collaborations and were connected only with municipalities. The municipal, 
nongovernmental organization, and education sectors each reported numerous intersector collaborations. Municipalities were identified as the most common partner when collaborating.

In an effort to unpack the nature of these collaborations, interviewees were asked about the frequency and nature of these collaborations. Responses were coded into categories of "ongoing relationships" and "occasional partnerships." Interviewees indicated that more than half of all collaborations were ongoing and that the remaining collaborations were occasional partnerships, often for the purposes of a specific project. The education and media sector as well as the municipal sector reported mostly ongoing collaborations, whereas collaborations reported by the emergency management and environmental management sectors tended to be more occasional. Three themes emerged from coding the responses from interviewees, and the labels affixed, i.e., "working relationship," "information sharing," and "resource coordination," convey the nature of the collaboration as expressed by the interviewees. It is important to recognize that these codes are not mutually exclusive and that collaborations may be coded into one or more themes. The majority of collaborations were categorized as working relationships. Working relationships were present in all sectors but were most common for municipal stakeholders and education and media. Information sharing occurred in all sectors except business and agriculture. Resource coordination collaborations were not reported often but were identified by environmental nongovernmental organizations, education and media, and environmental management groups.

Bridging organizations are of particular interest in a socialecological inventory because they play an essential role in connecting actors within diverse networks across levels and coordinating information, perceptions, and resources. These organizations serve as key points to access existing networks. Interviewees were asked to identify a bridging organization in the Niagara Region concerning environmental management, protection, or risk management. It is important to note that the second most common theme when coding responses to this question was the lack of a bridging organization within the region. This perception was identified within all stakeholder groups. The Niagara Region was the organization most often identified as a bridging organization; interviewees with a municipal affiliation in particular perceived the region as "best positioned" to act as a bridging organization. Several interviewees also identified the Niagara Peninsula Conservation Authority as a bridging organization. Interviewees considered the Niagara Peninsula Conservation Authority to be a bridging organization because of its understanding of ecosystem functions, management of numerous environmentally sensitive areas, critical input into landuse planning, and considerable linkages with government agencies as well as to the nongovernmental sector.

\section{DISCUSSION}

In keeping with the exploration of the social-ecological inventory as a tool for priming ACM concerning climate change adaptation, we discuss several of the insights gained through the Niagara case study about how the social-ecological inventory tool appears to have catalyzed the initiation of an ACM process. This has occurred by facilitating the identification and selection of diverse public and private stakeholders and probing local knowledge, perceptions of, and linkages within the social-ecological system that could be utilized to minimize tensions inherent in approaches that join the public and private domains. The data collected through the social-ecological inventory tool were specifically oriented toward the initiation of a participatory process, in this case an ACM process, and provided valuable insights into the aspects of ACM that were fulfilled by the actors and those aspects that were not. The research team used this information to bring together a group of actors and provide a platform for an ACM process.

\section{Diverse knowledge types}

Scientific and local knowledge are both recognized as playing important roles in climate change adaptation (Berkes 2009b, Nilsson and Gerger Swartling 2009). Often, the delineation between local and scientific knowledge is blurred (Folke et al. 2003), and this was evident in the Niagara Region. In undertaking the social-ecological inventory in Niagara, local knowledge held by stakeholders was revealed. Although the specific knowledge and depth varied, many sources of local knowledge were identified. For example, one stakeholder was extremely knowledgeable about tree canopies, whereas another had considerable insights about community gardens. The socialecological inventory also highlighted gaps in scientific and/or local knowledge and permitted actors an opportunity to identify information they would like to acquire. For example, many actors expressed the following: "We know the global or national predictions for climate change, but what does this mean for us in Niagara?" "How do we adapt when we're not sure what we should be adapting to?" ACM provides a process by which different types of knowledge can be combined, cogenerated, and used (Berkes 2009b, Armitage et al. 2011). The initiation of the ACM process by the research team brought the diverse experiential and scientific knowledge held by local actors in the community together and provided an opportunity to fill the knowledge gaps perceived by the local actors.

Developing an understanding of stakeholders' knowledge and activities before undertaking ACM was immensely beneficial in the Niagara case because it allowed the research team to streamline and tailor the process in several ways. For example, information gained through the social-ecological inventory about knowledge, activities, and efforts of stakeholders facilitated introductions among actors. The expressed interest in gaining information via climate models about changes and impacts specific to the Niagara Region allowed an entry point to engage actors in the ACM process through an information workshop. The social-ecological inventory also helped to illuminate potential differences that could act as barriers in the early stages of ACM. In particular, it made the research team aware of value differences held by actors.

\section{Social-ecological system perceptions and linkages}

Collaboration is one pillar of ACM, and relationships are an essential ingredient in the process as they build trust, help to resolve conflicts, and assist with sharing power (Berkes 2007, Armitage et al. 2009). The social-ecological inventory made the research team aware of existing conflicts between and among stakeholders and revealed information about past collaborative efforts that had not ended well. Actors reacted positively to Brock University initiating the ACM process through the application of 
the social-ecological inventory and expressed that it provided an unbiased organization without ulterior motives. Power sharing is often a particularly difficult issue in collaboration, and through the social-ecological inventory, we were able gain insights into the concerns of participants in this regard. Specifically, most of the actors considered the Niagara Region to hold the most power in making decisions about climate change and expressed concern that this power was not shared with other groups. Although it is certainly not always the case, the process of ACM is documented to build trust, resolve conflicts, and mediate power differences (Folke et al. 2005, Plummer and FitzGibbon 2007, Armitage et al. 2009). Insights about conflicts and power differentials gained through the social-ecological inventory assisted with facilitating these challenges in the early stages of the ACM process. For example, actors were able to express their concerns that the region was "in charge" of climate change, and conversely, the region was able to enter into dialogue about its desire to engage with stakeholders and together pursue an integrative approach to community-based adaptation. Trust appeared to have increased among the core group of actors who have interacted on a regular basis for more than a year.

The role of social networks is emphasized in adaptive governance (Folke et al. 2005, Olsson et al. 2006), and in ACM, these networks connect actors horizontally and vertically to build trust and enable social learning (Plummer and FitzGibbon 2007, Armitage et al. 2009). In drawing on experiences in Kristianstads Vattenrike, Olsson et al. (2007:274) observe how "these networks facilitate information flows, identify knowledge gaps, and create nodes of expertise that are of significance for ecosystem management." The social-ecological inventory provided key insights into the frequency and number of collaborative connections within and between sectors. It also helped in understanding the nature of exchanges, i.e., working relationships, information sharing, and resource coordination, taking place through these collaborative networks. The social-ecological inventory in the Niagara case was especially valuable in illuminating potential bridging organizations, e.g., the Niagara Region and the Niagara Peninsula Conservation Authority, as well as their perceived absence. The research team was thus able to pay particular attention to fulfilling this bridging function during the early stages of the process. Ensuring the presence and function of social networks is critical because these networks are identified as sources of resilience in social-ecological systems (Hahn et al. 2008). Bridging organizations in particular offer lessons for nurturing resilience and may be mobilized when required (Schultz 2009).

\section{CONCLUSIONS}

Adapting to climate change is imperative and will require action from the private domain as well as public actors. Thus, governance has a critical role to play in this process. ACM offers a way to make adaptive governance operational and does so by engaging actors in a collaborative and learning-oriented process. In this way, it coincides with emerging directions in climate adaptation. For example, Nilsson and Gerger Swartling (2009:3) write that "in order to affect underlying values, the literature emphasizes social learning as an on-going social process focused on dialogue and exchange that can incorporate knowledge from various perspectives and different social levels." However, experiences with ACM suggest that it can take a substantial amount of time to evolve (Armitage et al. 2009, Berkes 2009a). Tools to accelerate such processes have great value as we consider the relatively short window of opportunity for climate change adaptation (Parry et al. 2009).

We explored the social-ecological inventory as a tool for priming the governance system for climate change adaptation. The sixstep process was applied in the Niagara Region of Canada over a six-month period as a precursor to undertaking an ACM. The social-ecological inventory appeared to have catalyzed ACM in a myriad of ways. Insights gained about networks and relationships permitted identification of key actors and bridging organizations. Local sources of knowledge were revealed, and gaps in knowledge were illuminated. Tailoring the ACM process was possible with an awareness of existing actions, desired information, and differences of values.

Three key future avenues for social-ecological inventories in relation to climate change adaptation have emerged from this exploratory work. The tool has been applied in only two contexts, i.e., Sweden and Canada, which are similar in respect to their development. An opportunity thus exists to apply the socialecological inventory in a variety of other contexts and to consider its performance. The social-ecological inventory tool was designed to be used by several audiences, including researchers, resource management organizations, and citizens. Experiences with the tool thus far come from the research community. It is anticipated that valuable insights and feedback on the tool would stem from its uptake by resource managers, resources users, and others. Possibilities also exist to design and conduct future research on the social-ecological inventory tool. For example, comparative studies would be required to precisely ascertain the extent to which conducting a social-ecological inventory prior to implementing an ACM process catalyzes ACM and alleviates potential tensions between the public and private domains. Incorporating insights gained from pursuing these opportunities into the social-ecological inventory tool will enhance the breadth of its applicability and its effectiveness.

\section{Responses to this article can be read online at: http://www.ecologyandsociety.org/issues/responses. $\mathrm{php} / 6152$}

\section{Acknowledgments:}

The authors thank all the participants in the research project associated with this paper. We are also grateful for the insights and contributions of Brad May, Samantha Purdy, and Jonas Velaniškis. Financial support for the research came from Environment Canada through a Grants and Contributions Agreement with Brock University. Finally, we wish to thank the reviewers and editors from "The Governance of Adaptation" symposium and Ecology and Society who provided valuable feedback on the manuscript.

\section{LITERATURE CITED}

Adger, W. N., S. Agrawala, M. M. Q. Mirza, C. Conde, K. O'Brien, J. Pulhin, R. Pulwarty, B. Smit, and K. Takahashi. 2007. Assessment of adaptation practices, options, constraints and capacity. Pages 717-743 in M. L. Parry, O. F. Canziani, J. P. 
Palutikof, P. J. van der Linden, and C. E. Hanson, editors. Climate change 2007: impacts, adaptation and vulnerability. Contribution of Working Group II to the Fourth Assessment Report of the Intergovernmental Panel on Climate Change. Cambridge University Press, Cambridge, UK.

Adger, W. N., and J. Barnett. 2009. Four reasons for concern about adaptation to climate change. Environment and Planning $A$ 41:2800-2805. http://dx.doi.org/10.1068/a42244

Agrawal, A. 2010. Local institutions and adaptation to climate change. Pages 173-197 in R. Mearns and A. Norton, editors. Social dimensions of climate change: equity and vulnerability in a warming world. The World Bank, Washington, D.C., USA.

Armitage, D., F. Berkes, A. Dale, E. Kocho-Schellenberg, and E. Patton. 2011. Co-management and the co-production of knowledge: learning to adapt in Canada's Arctic. Global Environmental Change 21(3):995-1004. http://dx.doi.org/10.1016/ j.gloenvcha.2011.04.006

Berkes, F. 2007. Adaptive co-management and complexity: exploring the many faces of comanagement. Pages 19-38 in D. Armitage, F. Berkes, and N. Doubleday, editors. Adaptive comanagement: collaboration, learning and multilevel governance. University of British Columbia Press, Vancouver, British Columbia, Canada.

Berkes, F. 2009a. Evolution of co-management: role of knowledge generation, bridging organizations and social learning. Journal of Environmental Management 90:1692-1702. http://dx.doi.org/10.1016/ j.jenvman.2008.12.001

Berkes, F. 2009b. Indigenous ways of knowing and the study of environmental change. Journal of the Royal Society of New Zealand 39(4):151-156. http://dx.doi.org/10.1080/03014220909510568

Berkes, F., J. Colding, and C. Folke, editors. 2003. Navigating social-ecological systems: building resilience for complexity and change. Cambridge University Press, Cambridge, UK. http://dx. doi.org/10.1017/CBO9780511541957

Berkes, F., and C. Folke, editors. 1998. Linking social and ecological systems. Management practices and social mechanisms for building resilience. Cambridge University Press, Cambridge, UK.

Burton, I., S. Huq, B. Lim, O. Pilifosova, and E. L. Schipper. 2002. From impacts assessment to adaptation priorities: the shaping of adaptation policy. Climate Policy 2:145-159. http://dx.doi. org/10.1016/S1469-3062(02)00038-4

Cummings, G. S. 2011. Spatial resilience in social-ecological systems. Springer, Dordrecht, The Netherlands. http://dx.doi. org/10.1007/978-94-007-0307-0

Cundill, G., and C. Fabricius. 2009. Monitoring in adaptive comanagement: toward a learning based approach. Journal of Environmental Management 90:3205-3211. http://dx.doi.org/10.1016/ j.jenvman.2009.05.012

Driessen, P. P. J., P. Glasbergen, and C. Verdaas. 2001. Interactive policy-making - a model of management for public works. European Journal of Operational Research 128:322-337. http://dx. doi.org/10.1016/S0377-2217(00)00075-8
Folke, C., J. Colding, and F. Berkes. 2003. Synthesis: building resilience and adaptive capacity in social-ecological systems. Pages 352-387 in F. Berkes, J. Colding, and C. Folke, editors. Navigating social-ecological systems: building resilience for complexity and change. Cambridge University Press, Cambridge, UK. http://dx.doi.org/10.1017/CBO9780511541957.020

Folke, C., T. Hahn, P. Olsson, and J. Norberg. 2005. Adaptive governance of social-ecological systems. Annual Review of Environment and Resources 30:441-473. http://dx.doi.org/10.1146/ annurev.energy.30.050504.144511

Gadgil, M., F. Berkes, and C. Folke. 1993. Indigenous knowledge for biodiversity conservation. Ambio 22:151-156.

Gadgil, M., P. Olsson, F. Berkes, and C. Folke. 2003. Exploring the role of local ecological knowledge in ecosystem management: three case studies. Pages 189-209 in F. Berkes, J. Colding, and C. Folke, editors. Navigating social-ecological systems: building resilience for complexity and change. Cambridge University Press, Cambridge, UK. http://dx.doi.org/10.1017/CBO9780511541957.013

Gallopín, G. C. 2006. Linkages between vulnerability, resilience, and adaptive capacity. Global Environmental Change 16 (3):293-303. http://dx.doi.org/10.1016/j.gloenvcha.2006.02.004

Glasbergen, P. 1998. The question of environmental governance. Pages 1-18 in P. Glasbergen, editor. Co-operative environmental governance: public-private agreements as a policy strategy. Kluwer Academic, Dordrecht, The Netherlands. http://dx.doi. org/10.1007/978-94-011-5143-6 1

Gunderson, L., and S. S. Light. 2006. Adaptive management and adaptive governance in the everglades ecosystem. Policy Sciences 39:323-334. http://dx.doi.org/10.1007/s11077-006-9027-2

Hahn, T., L. Schultz, C. Folke, and P. Olsson. 2008. Social networks as sources of resilience in social-ecological systems. Pages 119-148 in J. Norberg and G. Cumming, editors. Complexity theory for a sustainable future. Columbia University Press, New York, New York, USA.

IPCC. 2001. Climate change 2001: impacts, adaptation, and vulnerability. Contribution of Working Group II to the Third Assessment Report of the Intergovernmental Panel on Climate Change. Cambridge University Press, Cambridge, UK.

IPCC. 2012. Summary for policymakers. Pages 3-21 in C. B. Field, V. Barros, T. F. Stocker, D. Qin, D. J. Dokken, K. L. Ebi, M. D. Mastrandrea, K. J. Mach, G.-K. Plattner, S. K. Allen, M. Tignor, and P. M. Midgley, editors. Managing the risks of extreme events and disasters to advance climate change adaptation. A Special Report of Working Groups I and II of the Intergovernmental Panel on Climate Change. Cambridge University Press, Cambridge, UK.

Kallis, G., M. Kiparsky, and R. Norgaard. 2009. Collaborative governance and adaptive management: lessons from California's CALFED water program. Environmental Science \& Policy 12 (6):631-643. http://dx.doi.org/10.1016/j.envsci.2009.07.002

Kiker, G. A., T. S. Bridges, A. Varghese, T. P. Seager, and I. Linkov. 2005. Application of multicriteria decision analysis in environmental decision making. Integrated Environmental 
Assessment and Management 1(2):95-108. http://onlinelibrary. wiley.com/doi/10.1897/IEAM_2004a-015.1/full

Klein, R. J. T., S. Huq, F. Denton, T. E. Downing, R. G. Richels, J. B. Robinson, and F. L. Toth. 2007. Inter-relationships between adaptation and mitigation. Pages 745-777 in M. L. Parry, O. F. Canziani, J. P. Palutikof, P. J. van der Linden, and C. E. Hanson, editors. Climate change 2007: impacts, adaptation and vulnerability. Contribution of Working Group II to the Fourth Assessment Report of the Intergovernmental Panel on Climate Change. Cambridge University Press, Cambridge, UK.

Kooiman, J. 2003. Governing as governance. Sage, Thousand Oaks, California, USA.

Lee, M. 2003. Conceptualizing the new governance: a new institution of social coordination. Paper presented at the Institutional Analysis and Development Mini-Conference, Workshop in Political Theory and Policy Analysis, May 3 and 5, Indiana University, Bloomington, Indiana, USA.

Lemos, M. C., and A. Agrawal. 2006. Environmental governance. Annual Review of Environment and Resources 31:297-325. http:// dx.doi.org/10.1146/annurev.energy.31.042605.135621

Locatelli, B., M. Kanninen, M. Brockhaus, C. J. Pierce Colfer, D. Murdiyarso, and H. Santoso. 2008. Facing an uncertain future: how forests and people can adapt to climate change. Forest Perspectives No. 5. Center for International Forestry Research, Bogor, Indonesia. [online] URL: http://www.cifor.org/publications/ pdf files/media/CIFOR adaptation.pdf

May, B., and R. Plummer. 2011. Accommodating the challenges of climate change adaptation and governance in conventional risk management: adaptive collaborative risk management (ACRM). Ecology and Society 16(1): 47. [online] URL: http://www. ecologyandsociety.org/vol16/iss1/art47/

Mushove, P., and C. Vogel. 2005. Heads or tails? Stakeholder analysis as a tool for conservation area management. Global Environmental Change 15:184-198. http://dx.doi.org/10.1016/j. gloenvcha.2004.12.008

Nelson, D. R., W. N. Adger, and K. Brown. 2007. Adaptation to environmental change: contributions of a resilience framework. Annual Review of Environment and Resources 32:395-419. http:// dx.doi.org/10.1146/annurev.energy.32.051807.090348

Niagara Economic Development Corporation (NEDC). 2010. Economic profile. NEDC, Thorold, Ontario, Canada. [online] URL: http://www.niagaracanada.com/INVEST-IN-NIAGARA/ Economic-Profile/

Nilsson, A. E., and Å. Gerger Swartling. 2009. Social learning about climate adaptation: global and local perspectives. Stockholm Environment Institute (SEI) Working Paper. SEI, Stockholm, Sweden. [online] URL: http://www.sei-international.org/mediamanager/ documents/Publications/Policy-institutions/social_learning_wp_091112. pdf

Olsson, P., C. Folke, V. Galaz, T. Hahn, and L. Schultz. 2007. Enhancing the fit through adaptive co-management: creating and maintaining bridging functions for matching scales in the Kristianstads Vattenrike Biosphere Reserve Sweden. Ecology and
Society 12(1): 28. [online] URL: http://www.ecologyandsociety. org/vol12/iss1/art28/

Olsson, P., L. H. Gunderson, S. R. Carpenter, P. Ryan, L. Lebel, C. Folke, and C. S. Holling. 2006. Shooting the rapids: navigating transitions to adaptive governance of social-ecological systems. Ecology and Society 11(1): 18. [online] URL: http://www. ecologyandsociety.org/vol11/iss1/art18/

Parry, M., N. Arnell, P. Berry, D. Dodman, S. Fankhauser, C. Hope, S. Kovats, R. Nicholls, D. Satterthwaite, R. Tiffin, and T. Wheller. 2009. Assessing the costs of adaptation to climate change: a review of the UNFCCC and other recent estimates. International Institute for Environment and Development and Grantham Institute for Climate Change, London, UK.

Plummer, R. 2006. Sharing the management of a river corridor: a case study of the co-management process. Society and Natural Resources 19:709-721. http://dx.doi.org/10.1080/08941920600801132

Plummer, R., and J. E. FitzGibbon. 2007. Connecting adaptive co-management, social learning and social capital through theory and practice. Pages 38-61 in D. Armitage, F. Berkes, and N. Doubleday, editors. Adaptive co-management: collaboration, learning and multilevel governance. University of British Columbia Press, Vancouver, British Columbia, Canada.

Prell, C., K. Hubacek, and M. Reed. 2009. Stakeholder analysis and social network analysis in natural resource management. Society and Natural Resources 22(6):501-518. http://dx.doi. org/10.1080/08941920802199202

Qureshi, M. E., S. R. Harrison, and M. K. Wegener. 1999. Validation of multicriteria analysis models. Agricultural Systems 62(2):105-116. http://dx.doi.org/10.1016/S0308-521X(99)00059-1

Saldaña, J. 2009. The coding manual for qualitative research. Sage, Thousand Oaks, California, USA.

Schultz, L. 2009. Nurturing resilience in social-ecological systems: lessons learned from bridging organizations. Stockholm University, Stockholm, Sweden.

Schultz, L., C. Folke, and P. Olsson. 2007. Enhancing ecosystem management through social-ecological inventories: lessons from Kristianstads Vattenrike, Sweden. Environmental Conservation 34 (2):140-152. http://dx.doi.org/10.1017/S0376892907003876

Schultz, L., R. Plummer, and S. Purdy. 2011. Applying a socialecological inventory: a workbook for finding the key actors and engaging them. Resilience Alliance. [online] URL: http://www. stockholmresilience.org/download/18.1f74f76413071d337c380004085/1381790163553/RA+workbook+final.pdf

Sjöberg, L. 2000. Factors in risk perception. Risk Analysis 20 (1):1-12. http://dx.doi.org/10.1111/0272-4332.00001

Smit, B., and J. Wandel. 2006. Adaptation, adaptive capacity and vulnerability. Global Environmental Change 16:282-292. http://dx. doi.org/10.1016/j.gloenvcha.2006.03.008

Smith, J. B., S. H. Schneider, M. Oppenheimer, G. W. Yohe, W. Hare, M. D. Mastrandrea, A. Patwardhan, I. Burton, J. CorfeeMorlot, C. H. D. Magadza, H.-M. Füssel, A. B. Pittock, A. Rahman, A. Suarez, and J.-P. van Ypersele. 2009. Assessing 
dangerous climate change through an update of the Intergovernmental Panel on Climate Change (IPCC) "reasons for concern." Proceedings of the National Academy of Science of the United States of America 106(11):4133-4137. http://dx.doi. org/10.1073/pnas.0812355106

Statistics Canada. 2012. Census profile (Niagara, Ontario). Statistics Canada, Ottawa, Ontario, Canada. [online] URL: http://www12.statcan.gc.ca/census-recensement/2011/dp-pd/prof/ details/page.cfm?Lang $=\mathrm{E} \& \mathrm{Geo} 1=\mathrm{CD} \& \mathrm{Code} 1=3526 \& \mathrm{Geo} 2=$ $\underline{\text { PR } \& \text { Code } 2=35 \& \text { Data }=\text { Count } \& \text { SearchText }=\text { Niagara } \& \text { SearchType }=}$

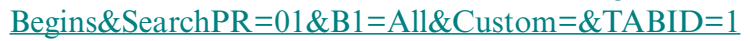

Tompkins, E. L., and H. Eakin. 2012. Managing private and public adaptation to climate change. Global Environmental Change 22:3-11. http://dx.doi.org/10.1016/j.gloenvcha.2011.09.010

Tompkins, E. L., R. Few, and K. Brown. 2008. Scenario-based stakeholder engagement: incorporating stakeholders preferences into coastal planning for climate change. Journal of Environmental Management 88(4):1580-1592. http://dx.doi.org/10.1016/j. jenvman.2007.07.025

van Nieuwaal, K., P. Driessen, T. Spit, and C. Termeer. 2009. A state of the art of governance literature on adaptation to climate change: towards a research agenda. IOP Conference Series: Earth and Environmental Science 6:362019. http://dx.doi. org/10.1088/1755-1307/6/36/362019

Witte, J. M., C. Streck, and T. Benner. 2003. The road from Johannesburg: what future for partnerships in global environmental governance? Pages 59-84 in T. Benner, C. Streck, and J. M. Witte, editors. Progress or peril? Partnerships and networks in global environmental governance. The postJohannesburg agenda. Global Public Policy Institute, Berlin, Germany. 